\title{
Characterization of Hazardous Constituents in HLW Supernate and Implications for Solid LLW Generation (U)
}

by

G. K. Georgeton

Westinghouse Savannah River Company

Savannah River Site

Aiken, South Carolina 29808

DOE Contract No. DE-AC09-89SR18035

This paper was prepared in connection with work done under the above contract number with the U.S.

Department of Energy. By acceptance of this paper, the publisher and/or recipient acknowledges the U.S.

Government's right to retain a nonexclusive, royalty-free license in and to any copyright covering this paper, along with the right to reproduce and to authorize others to reproduce all or part of the copyrighted paper. 


\section{DISCLAIMER}

This report was prepared as an account of work sponsored by an agency of the United States Government. Neither the United States Government nor any agency thereof, nor any of their employees, makes any warranty, express or implied, or assumes any legal liability or responsibility for the accuracy, completeness, or usefulness of any information, apparatus, product, or process disclosed, or represents that its use would not infringe privately owned rights. Reference herein to any specific commercial product, process, or service by trade name, trademark, manufacturer, or otherwise does not necessarily constitute or imply its endorsement, recommendation, or favoring by the United States Government or any agency thereof. The views and opinions of authors expressed herein do not necessarily state or reflect those of the United States Government or any agency thereof.

This report has been reproduced directly from the best available copy.

Available to DOE and DOE contractors from the Office of Scientific and Technical Information, P.O. Box 62, Oak Ridge, TN 37831; prices available from (615) 576-8401.

Available to the public from the National Technical Information Service, U.S. Department of Commerce, 5285 Port Royal Road, Springfield, VA 22161. 


\section{DISCLAIMER}

Portions of this document may be illegible in electronic image products. Images are produced from the best available original document. 
HIGH LEVEL WASTE ENGINEERING

TANK FARM STUDIES SECTION

UNCLASSIFIED

DOTS MOT SORT MN

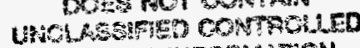

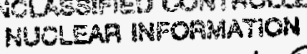

ADS:

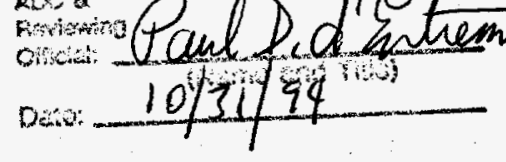

WSRC-TR-94-0297

REVISION: 1

KEYWORDS:

High Level Waste

Engineering, Mercury,

Chromium, Lead, Silver

Benzene, TCLP

RETENTION:

PERMANENT

CLASSIFICATION:

UNCLASSIFIED

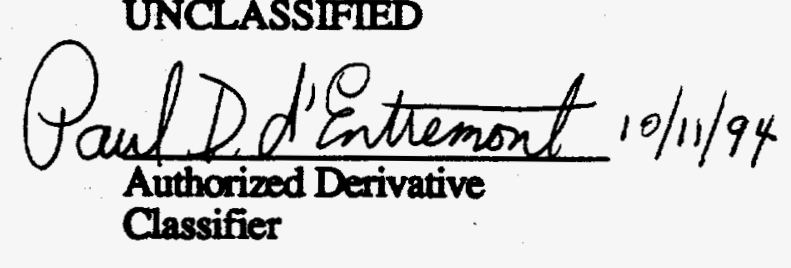

CHARACTERIZATION OF HAZARDOUS CONSTITUENTS IN HL SUPERNATE AND IMPLICATIONS FOR SOLID LEW GENERATION

BX

G. K. GEORGETON

October 10, 1994

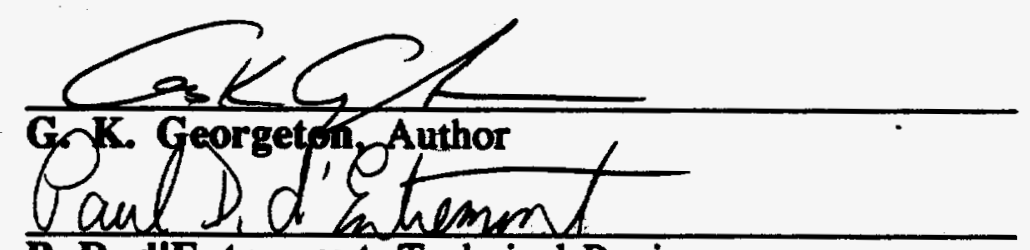

P. D. d'Entremont, Technical Reviewer

Douglas Orterom

D. F. Brown, Technical Reviewer

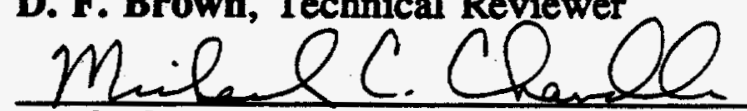

M. C. Chandler, Manager, Waste Characterization Group Th s. Mem

J. E. Marta, Manager, HLWE Support Group

yedictert for

T. M. Monahon, Manager, HLWE
Date: $10 / 11 / 94$

Date: $10 / 4 / 94$

Date: $10 / 11 / 94$

Date: $10 / 12 / 94$

Date: $10 / 12 / 94$

Date: $10 / 26 / 94$ 
WSRC-TR-94-0297

Revision 1

Page 2 of 29

\section{Revision_History:}

\begin{tabular}{ccl} 
Revision & Date & \multicolumn{1}{c}{ Changes } \\
\hline 0 & $6 / 22 / 94$ & - Initial Issue \\
1 & $10 / 10 / 94$ & $\begin{array}{l}\text { - Expanded Screening Criteria to provide guidance for waste } \\
\text { payloads up to } 5000 \text { lb and 137 Cs loading up to 6.2 Ci } \\
\text { - Presented Criteria in graphical format } \\
\text { - Included category of Average Supernate, and demonstrated } \\
\text { conservatism of Screening Criteria with calculations for } \\
\text { Average Supernate }\end{array}$
\end{tabular}




\section{TABLE OF CONTENTS}

Introduction 4

Summary 5

Discussion

Identification of Hazardous Constituents 6

Impact of HLW Processing on Hazardous Constituents

Supernate Characterization $\quad 11$

Implications for Solid Waste Generation $\quad 15$

Comparison with Average Supernate 18

Actions

19

References $\quad 19$

$\begin{array}{ll}\text { Attachment A } & 29\end{array}$

\section{LIST OF TABLES}

Table I. Potential Hazardous Constituents in HLW 21

Table II. Concentrations of Hazardous Constituents in Samples of 22 Traditional Supernate

Table III. Concentrations of Hazardous Constituents in Samples of 23 Dilute Supernate

Table IV. Concentrations of Hazardous Constituents in Samples of Sludge Processing Supernate

Table V. Characterization of Hazardous Constituents in HLW Supernates

Table VI. Relative Importance of Hazardous Constituents in HLW Supernates

\section{LIST OF FIGURES}

Figure 1. Simulated TCLP Leachate for 'TS Contaminated Solid Waste 25

Figure 2. Simulated TCLP Leachate for SPS Contaminated Solid Waste 26

Figure 3. Screening Criteria for Supernate Contaminated Solid Waste 27

Figure 4. Comparison of Individual Supernate Criteria to Criteria Based 28 on Average Supernate Characterization 
WSRC-TR-94-0297

Revision 1

Page 4 of 29

\section{INTRODUCTION}

High Level Waste (HLW) generated during Separations processing in the F- and $\mathrm{H}$-Canyons is transferred to the Tank Farms for storage in 51 underground, million gallon storage tanks. The waste is an aqueous solution containing dissolved sodium salts and insoluble metal oxides/hydroxides. The waste solution is evaporated to reduce the volume, and the resulting saltcake and residual supernate are stored. Eventually, the soluble and insoluble components will be separately prepared for processing within the DWPF for final disposal.

Over the $\mathbf{4 0}$ year history of the Tank Farm, routine supernate sampling has been conducted in support of the primary goal of safe storage of $\mathrm{HLW}$. Special samples have also been collected to support the corrosion prevention program and the development of the DWPF and associated facilities. Because of the costs (in dotlars and personnel exposure) involved in collection, preparation and detailed analysis of samples, the extent of the analysis was limited. Detailed component concentrations were estimated using process knowledge and complemented with the limited analytical data. However, with the changing mission of the Tank Farms, and equally important, compliance with regulatory requirements, more detailed information on waste characterization is necessary.

As a result of routine and non-routine activities that are part of managing these highly radioactive wastes, secondary solid waste is generated. Items such as protective clothing, plastic for contamination prevention, contaminated tools, etc. are collected for disposal in B-25 and B-12 waste boxes. Infrequent and non-routine activities also generate quantities of solid waste (e.g., transfer piping, pumps, potentially contaminated soil). Radioactive contamination of over $90 \%$ of the solid waste generated is due to contact with HLW supernate or saltcake. In order to comply with the Waste Acceptance Criteria (WAC) for disposal of solid waste in the E-Area Vaults (EAV), the quantity of certain radioisotopes must be manifested for each waste container and a declaration made of whether or not the waste is hazardous. However, solid waste is not amenable to routine smearing and analysis to determine the required data. Waste which has been contaminated with enough supernate for a smear to be meaningful typically has too high a dose to allow collection of the smear, whereas waste that can be smeared without dose concerns is not contaminated with enough waste to allow detection of most components. Further, obtaining representative smear samples is impractical due to the number of different items in the waste containers. Thus, this forces a reliance on analytical data from supernate samples to characterize the contamination. Unfortunately, such data are difficult and costly to obtain.

To provide the manifest information, process knowledge in combination with the limited amount of analytical data will be used. This report documents the characterization of hazardous components in the HLW supernate associated with the waste storage, evaporation and sludge processing facilities. (The supernate associated with salt removal and the In-Tank Procipitation Facility will be addressed at a later time. Characterization of the hazardous components in HLW sludge will also be addressed separately.) The hazardous constituents of HLW are identified and the fate of the constituents is tracked based on knowledge of each phase of the process. The limited amount of sample data that includes analyses for hazardous species is then used to establish average and maximum characterization values. The concentration of the components in leachate from solid waste contaminated with supernate is calculated and compared with the RCRA regulations, thereby providing a screening tool to distinguish between waste containers that are definitely nonhazardous and containers that require additional evaluation. Finally, a screening criterion based on an average supernate characterization is compared to the criteria for the individual streams to evaluate the amount of conservatism introduced for the individual streams. 
WSRC-TR-94-0297

Revision 1

Page 5 of 29

\section{SUMMARY}

A study was conducted to characterize the concentrations of hazardous constituents in High Level Waste supernate to support manifesting of packages of solid waste contaminated with supernate. A simple method was developed to screen waste containers to identify those containers that are nonhazardous with respect to the supernate contamination.

High Level Waste supernates are hazardous due to the presence of small quantities of mercury, chromium and lead. The supernates were grouped into Traditional (normal storage and evaporation), Dilute (stored in Type IV tanks), Sludge Processing (Tanks 40, 42 and 51) and Average (all tanks except ITP) categories. (Supernate associated with salt removal and the In-Tank Precipitation Facility will be characterized separately. Characterization of the hazardous components in HLW sludge will also be addressed separately.) The fate of the hazandous components was evaluated based on process knowledge. A review of the limited quantity of available sample data for each type of supernate was performed. Based on the data and process knowledge, the maximum concentration of each hazardous constituent was determined, and the constituent present in the greatest ratio to the regulatory limit was defined as most restrictive. The most restrictive hazardous constituent in Traditional, Sludge Processing and Average supernates was determined to be mercury, and the most restrictive component in Dilute supernate was determined to be chromium. The concentration of the most restrictive component in the leachate from a Toxicity Characteristic Leaching Procedure (TCLP) was linked to the ${ }^{137} \mathrm{Cs}$ content of a waste package to develop the screening criteria.

The screening criteria for waste contaminated with supernate from normal storage and evaporation operations (Traditional Supernate) and from sludge processing operations (Sludge Processing Supernate) are presented in Figure 3. The ${ }^{137} \mathrm{Cs}$ content of a waste package is obtained from doseto-curie conversion of field measurements of radiation exposure rates. For a given type of supernate contamination, the ${ }^{137} \mathrm{Cs}$ content and the waste payload are compared to the appropriate line in Figure 3. Waste containers that fall below the line are definitely nonhazardous (with respect to the supernate contamination) due to the extreme conservatism in the hazardous component characterization and ${ }^{137} \mathrm{Cs}$ concentrations. Waste packages that are above the line could contain hazardous waste and require segregation for additional evaluation before disposal. As a point of reference, containers with less than 0.62 Ci of ${ }^{137} \mathrm{Cs}$ (limit for the Low Activity Waste Vault, scaled to account for other isotopes) and over $500 \mathrm{lb}$ of solid waste contaminated with Traditional Supernate can be screened as nonhazardous. Similarly, containers with less than $0.62 \mathrm{Ci}$ of ${ }^{137} \mathrm{Cs}$ and over $1000 \mathrm{lb}$ of solid waste contaminated with Sludge Processing Supernate are nonhazardous. All containers of supernate contaminated waste from Type IV tanks (Dilute Supernate) were evaluated as being nonhazardous.

Most solid waste packages will be within the screening criteria, which is conservatively based on the lowest ${ }^{137} \mathrm{Cs}$ and highest hazardous component concentrations. The small number of containers outside the screening limits may still be nonhazardous due to the extreme conservativism in the method development, and these packages can be segregated for more detailed evaluation. Comparison of the screening criteria of the specific streams with the criterion developed for Average Supernate contamination reflects the large degree of conservatism. Finally, when used to screen the total solid waste stream from the Tank Farms (i.e., the entire quantity of waste as a single mass), calculations reflect that the total stream is nonhazardous. 
WSRC-TR-94-0297

Revision 1

Page 6 of 29

\section{DISCUSSION}

\section{Identification of Hazardous Constituents}

The HLW transferred to the Tank Farms is categorized as hazardous due to toxicity characteristics as a result of the concentration of several waste constituents, and as corrosive due to the high pH of the waste. The RCRA Part A Permit Application [1] (under which the Tank Farms operated before obtaining a Wastewater Permit) indicated that seven waste codes were present in HLW corrosivity, barium, chromium, lead, mercury, silver and benzene. The corrosivity categorization is not a concem within the context of this document, as explained below. Review of the regulated components for the Toxicity Characteristic Leaching Procedure [2] for solid wastes indicates that 5 of the regulated metals are already known to exist in the waste. The 3 remaining metals - arsenic, selenium and cadmium - will also be included in this analysis due to downstream feed requirements. Other compounds that are categorized as listed wastes, such as F-listed solvents, are not a concern because they are not used in any processes that generate HLW or for the reasons indicated below.

High Level Waste is categorized as corrosive due to the presence of hydroxide. The $\mathrm{pH}$ of fresh waste is greater than 14, as compared to the regulatory limit of 12.5 for corrosivity. The supernate is evaporated in Tank Farm evaporators to reduce the volume, concentrating the hydroxide and further increasing the $\mathrm{pH}$. However, the goal of this report is to develop a characterization to be applied to solid-waste. Regulatory requirements indicate that corrosivity applies to aqueous or liquid wastes [3]. Since no free liquid (i.e., less than $1 \%$ of any included liquid is unabsorbed) is allowed within a waste container, the hazard of corrosivity does not apply.

Mercury is used in the H-Canyon process as a catalyst to aid in the dissolution of the aluminum cladding of fuel tubes. Mercury has also been used in both F- and H-Canyons as a catalyst for the dissolution of Pu-Al targets and scrub alloy material. Upon addition of $\mathrm{NaOH}$ to the acidic waste stream, the $\mathrm{Hg}$ forms $\mathrm{HgO}$, which has a very low solubility. Mercuric oxide precipitates, mixing in with the remaining components as part of the sludge. Due to the high free hydroxide concentration in the supernate (>1M), a small fraction of the mercury remains soluble as the sodium salt of the $\mathrm{HgO}(\mathrm{OH})$ - ion.

Chromium is present in HLW from several sources. In the canyons, dissolution of stainless steel clad fuel tubes and corrosion of stainless steel vessels (due to use of dissolution catalysts) introduces quantities of $\mathrm{Cr}_{r}$ into the waste. Chromated solutions have been used in the past for target cleaning in the RBOF/RRF. Within the HLW tanks, some of the cooling coils have developed leaks, allowing the chromated cooling water to escape into the waste inventory. Because of the high hydroxide concentration in the fresh waste stream and that maintained in the waste tanks, chromium is present as the $\mathrm{CrO}_{4}=$ ion.

Silver as a fission product is present in the waste in very small concentrations. Non-radioactive silver has been transferred in the past to the waste tanks from the flushing of beds of silver-coated Berl saddles used to trap iodine in the canyons. The silver, upon reaction with hydroxide, forms the insoluble $\mathrm{Ag}_{2} \mathrm{O}$ and precipitates, with a small fraction remaining soluble as $\mathrm{NaAg}(\mathrm{OH})_{2}$.

Lead $(\mathrm{Pb})$ is present in HLW due to its use as a lubricant for coextruded fuel tubes. Arsenic (As), barium (Ba), selenium (Se) and cadmium ( $\mathrm{Cd}$ ) are not used in any of the processes (either as raw materials or as alloys used in equipment) that generate HLW, but were produced in SRS reactors as fission products or daughters of fission products. 
WSRC-TR-94-0297

Revision 1

Page 7 of 29

Benzene is potentially present in fresh waste due to its presence as an impurity in the n-paraffin diluent used in the Separation facilities. Because the organic material used in the canyon is extremely insoluble in the aqueous solutions, very little organic enters the aqueous HLW stream and the concentration is expected to be very small. (Benzene will be present in significant quantities in the In-Tank Precipitation processing tanks; however, the supernate in these tanks will be characterized at a later time.)

No listed wastes have been identified in HLW. Many of the components categorizod in regulatory documentation as hazardous are organic materials and are included as components of listed wastes. The only organic materials used within the canyons are tri-n-butyl phosphate (TBP) and an n-paraffin diluent. Laboratory facilities do use small quantities of chemicals that appear on the hazardous waste lists as part of their analytical methods. However, the use of these chemicals is covered by various RCRA exemptions and does not generate a hazardous waste. The laboratory streams are small in volume and are combined with other waste streams before reaching the HLW tanks. The South Carolina Department of Health and Environmental Control (SCDHEC) and the Environmental Protection Agency (EPA) reviewed and concurred with the position that there are no listed wastes in HLW [4]. More recently, a DOE Tiger Team suggested more stringent controls to prevent transfer of listed wastes to the Tank Farms, but did not dispute the earlier position [5].

As part of the management of HLW, addition of sodium hydroxide and sodium nitrite is occasionally performed to supplement the existing levels of these corrosion inhibitors in the waste. Maintenance within the facilities requires partial or complete decontamination to reduce exposure, and the spent solutions are transferred into the waste tanks. The chemical solutions used in these activities are controlled so that no hazardous components are added to the waste inventory.

The waste components to be characterized are presented in Table $I$. The fate of these components in the waste tanks depends on the various processing steps within the HLW system. In the evaluation that follows, discussion of the TCLP metals will be in general terms and complemented with specific information when available.

\section{Impact of HLW Processing on Hazardous Constituents}

\section{Waste Receipt and Storage}

High level liquid waste generated during operation of the Separations Canyons" consists of a nitric acid solution. Metals dissolved in the solution include sodium, iron, manganese, aluminum, uranium, fission products and several additional minor components, including the TCLP metals. Waste generated during the first cycle of the Separations process contains over $99 \%$ of the fission products [7] and is segregated as High Heat Waste (HHW). The remainder of the Canyon waste is segregated as low heat waste (LHW). Small losses of the TBP/n-paraffin mixture from the Canyon process are also present in the waste stream.

\# Periodically, waste is received from other, non-Separations facilities (e.g., Reactor ares sand filter backwash) and mixed with the traditional waste in the Tank Farms. Samples of typical waste from these facilities and from the Separations facilities were analyzed for several of the TCLP metals [6]. The concentrations of the metals in the waste from Separations facilities were several times higher than in waste from the other facilities. The quantities of the non-Separations waste are small relative to that generated during Canyon processing. Thus, this discussion for the entire volume of waste can be based on typical Separations waste. 
WSRC-TR-94-0297

Revision 1

Page 8 of 29

The waste solution is $\mathrm{pH}$ adjusted with sodium hydroxide $(\mathrm{NaOH})$ before transfer to the Tank Farms for storage in underground, carbon-steel tanks. The resulting slurry consists of relatively insoluble metal oxides/hydroxides in an aqueous solution of sodium salts. Theoretically, the metal oxides/hydroxides would be at their solubility limit in the aqueous solution. However, because the metals are dissolved and evenly distributed within the well mixed acid stream, the irreversible (in a thermodynamic sense) addition of hydroxide causes the rapid formation of particles. The metals "co-precipitate" with one another, forming mixtures and essentially scavenging metal oxides/hydroxides that might not have precipitated in as great a concentration under more controlled conditions. The quantity of metal that precipitates versus the quantity that stays soluble clearly depends on the process conditions and on the concentration of the metals in the initial acid solution, which can vary based on processing requirements within the Canyons. The presence of other components can alter the compounds that are formed during the reaction with hydroxide, thus affecting the solubility. Ultimately, the concentrations of TCLP (and other) metals in the supernatant liquid are small (mg/ levels), can be significantly different than the theoretical maximum of the solubility limit; and vary from batch to batch.

The waste slurry is initially received into a pump tank and is then transferred into the fresh waste receipt tank. The insoluble solids settle in the waste receipt tank, forming the sludge layer. The waste tank contents are not agitated, but some mixing of the supernate does occur due to convective currents created by the tank cooling coils. High heat waste is aged in the receipt tanks to allow short-lived fission products to decay, before the supernate is decanted to a feed tank to be volume reduced in an evaporator. Low heat waste does not require an aging period and is decanted directly from the fresh waste receipt tank to the evaporator.

The waste stream potentially contains minute quantities of benzene, which would have entered as an impurity in the n-paraffin diluent. The high salt content of the supernate acts to "salt out" the benzene, essentially increasing the Henry constant. The resulting benzene concentration would be small, and receipt of the liquid during transfer from the Canyon into the pump tank provides agitation to expose the benzene to the active ventilation system in the pump tanks. Similarly, any soluble benzene in the receipt tanks would gradually reach the liquid surface due to the agitation resulting from thermal currents in the tank. The active ventilation systems in the pump and waste receipt tanks would strip the benzene from air-waste interface. Thus, benzene is expected to be present only in the fresh waste receipt tanks, and then, only in trivial quantities. (Once the DWPF begins operation, the recycle stream to the Tank Farm will contain small amounts of benzene and phenoxide. This evaluation will have to be updated before the startup of the DWPF to address the impact of this new source of benzene.)

Periodically, waste supernates are transferred between tanks and combined with other volumes of supernate, primarily to provide a continuous supply of solution to be evaporated. The supernates have been processed to varying degrees, so the concentration of the components will vary. Mixing of the different supernates results in varying concentrations of the TCLP metals.

\section{Evaporation}

Supernate is processed in an evaporator to reduce the volume of waste to be stored. Part of the water is removed, and the resulting concentrate transferred to a separate tank. As water is removed, the concentration of all the salts and metals increases. If the concentration of the component in cooled concentrate is less than its solubility limit, then the component will remain in solution. If the concentration is above the solubility limit, the compound will precipitate. The 
supernate remaining after solids have precipitated is recycled to the evaporator feed tank to be combined with additional supernate. The cycle is repeated, such that a given volume of supernate may pass through the evaporator several times, each time having some of the water removed. In this manner, the volume of fresh canyon waste is reduced to approximately one-third of its original volume for storage.

The primary components that do precipitate are the sodium salts, forming saltcake containing 10-20 vol\% interstitial liquid. The sodium salts have various solubilities, so depending on the concentration in the cooled supernate, the least soluble salts will precipitate first. Sodium hydroxide is the most soluble and remains in solution. As the supernate is recycled several times, the hydroxide concentration continues to increase such that it is the dominant component in the evaporator concentrate.

During evaporation, the TCLP and other metals behave analogously to the sodium salts. The TCLP metals accumulate in the supernate until the individual solubility limits are reached as the solution becomes more concentrated. The metal that cemes out of solution is interspersed within the salt matrix in the concentrate receipt tank. Similarly, the interstitial fluid within the saltcake contains the soluble forms of the FCLP metals The accumulation of mercury, however, in the saltcake and supernate is lower relative to the other TCLP metals due to its volatility. A fraction of the dissolved (ionic) mercury is chemically reduced to its elemental form within the evaporator, and due to its high vapor pressure, is volatilized into the overheads. The quantity of $\mathrm{Hg}$ that leaves the system through the overheads versus the amount that remains in the evaporator concentrate to accumulate and/or precipitate in the saltcake has not been determined.

Benzene is very volatile, so evaporation of supernate drives off any remaining benzene that could be present. The Henry constant of benzene has been shown to increase as temperature increases [8], and the benzene would, therefore, vaporize in the evaporator even more readily than in the waste tanks. As the waste is concentrated in the evaporator, the increased sodium concentration further increases the Henry constant [8], thereby forcing even more benzene from solution. Thus, any benzene in the evaporator feed is removed from the system and does not accumulate in concentrated HIW.

The overheads from the evaporator are collected, condensed and sampled to ensure that adequate ${ }^{137} \mathrm{Cs}$ decontamination has been accomplished through evaporation. Trace quantities of waste are able to pass through the de-entrainment section of the evaporator, contaminating the overheads. Typical evaporator operation reduces the ${ }^{137} \mathrm{Cs}$ concentration by a factor of $10^{4}$ to $10^{6}$, and the volume of the supernate can be reduced by about one-third on the first pass through the evaporator. The elemental mercury that volatilizes into the overheads is physically separated from the aqueous portion of the overheads and recycled to the Canyons. The overheads are then transferred to the F/H Effluent Treatment Facility (ETF) for final polishing before discharge to NPDES outfalls on site.

The concentrations of the other TCLP metals in the overheads are also reduced by at least a factor of $10^{4}$. Because of its volatility, all the benzene in the supernate being evaporated is expected to be collected in the overheads in the first pass through the evaporator.

\section{Sludge Processing}

Settled sludge remains undisturbed in the waste tanks until it is transferred to the Sludge Processing (SP) tanks. A series of steps consisting of sludge suspension, settling and supernate 
WSRC-TR-94-0297

Revision 1

Page 10 of 29

decanting prepares the sludge to be fed to the DWPF. The sludge is reslurried in the present storage tank with either existing supernate or inhibited water, depending on availability. The slurry is transferred to the SP tanks, where the sludge settles. The supernate is decanted to an evaporator feed tank for processing or to a waste tank for reuse. Sludge that contains relatively high concentrations of aluminum is contacted with excess sodium hydroxide to chemically convert the aluminum to a soluble form. The solution is heated by direct steam injection and mixed for a period of several days. The reaction of Al reduces the aluminum content of the sludge, thereby reducing the volume of sludge. After a period for the solids to settle, the supernate is decanted for evaporation. The remaining sludge is washed with large batches of inhibited water to remove soluble species. Each batch of water is added and the tank contents agitated. Once the solids settle, the supernate is decanted to the evaporator feed tank for volume reduction. Several washing steps are performed to reduce the sodium concentration to a specified target value. When the washing criteria are satisfied, the sludge will be transferred in batches to the DWPF for processing.

In the initial slurrying step, supernate is used for the slurrying medium. The initial concentration of the TCLP metals can change during the slurrying step depending on how close the initial concentration of a particular metal in the supernate is to the solubility limit (i.e., driving force) and the quantity of each metal within the sludge. Suspending the sludge increases the contact of solids with the liquid, improving the conditions for dissolution (as discussed for sludge washing below). However, because of the co-precipitation of the many metals in fresh waste sludge, dissolution into supernate is slow relative to the times involved in the process. Thus, the concentration of the TCLP metals in the supernate that is decanted after slurry movement to the SP tanks would be, at most, at the solubility limit.

Once Al dissolution is started, some of the TCLP metals in the sludge can go into solution. During the full scale demonstration $[9,10,11,12]$, an increase in the quantity of soluble mencury and chromium in the supernate was observed. It is important to note that the concentrations of the $\mathrm{Hg}$ and $\mathrm{Cr}$ remained roughly the same; the $\mathrm{NaOH}$ and supernate added for processing provided additional "room" into which the components could dissolve. Mixing the sludgeat higher temperatures $\left(85^{\circ} \mathrm{C}\right)$ and higher hydroxide concentration promoted dissolution of certain metal oxides/hydroxides, freeing up other metals to begin dissolving. This was observed during the demonstration, when, as aluminum dissolved, uranium that had originally co-precipitated with the $\mathrm{Al}$ also dissolved [11]. The amount of dissolution depends on the solubility of the component and on the oxidation/reduction reactions that are favorable under the conditions in the tank (i.e., one component may become more soluble, while another may become less soluble due to a change in the valence state of the metal, while the solubility of some components will not change).

The washing steps also increase the potential for the TCLP and other metals to dissolve. Slurrying the sludge exposes all the solids to contact with the undersaturated wash water. Based on the relative concentrations between the supernate and the sludge (i.e., driving force) and on the dissolution kinetics with respect to the processing time, the effect on the metals varies. The concentrations of components that do not dissolve from the solids (either there is none in the sludge, or dissolution takes too long) are lowered through dilution. The concentrations of components that do dissolve readily are different than the concentrations resulting from simple dilution. In the SP demonstration, the concentrations of ${ }^{137} \mathrm{Cs}, \mathrm{Cr}$ and $\mathrm{Hg}$ did not decrease in a smooth, stepwise fashion, but the concentrations following each wash step indicated that any dissolution of these components was slow relative to the time scale of the process. Recent laboratory results from sludge washing experiments [13] do reflect the gradual decline that is characteristic of simple dilution of these components. Thus, for sludge washing, dissolution of the metals will be minimal. 
WSRC-TR-94-0297

Revision 1

Page 11 of 29

Based on the description of the storage and evaporation steps, benzene is not expected to be present in the aged sludge slumry transferred to SP.

\section{Supernate Characterization}

A waste characterization program has been in place since the Tank Farms began receiving waste to provide the information needed to safely receive and store HLW. However, in order to completely characterize the waste in the tanks to address the numerous issues and requests for data involving major, minor and trace constituents, analytical information would have to have been obtained for each batch of waste received from the generators, as well as for the various process streams within the HLW system (e.g., evaporator). The data could then have been used to complete a material balance for all species and their distribution within the tanks. Because of numerous reasons, an extremely rigorous sampling and analysis program is not practical or prudent (e.g., initial site mission to quickly produce plutonium, with work on waste disposal following later, the costs in dollars and personnel radiation exposure precludes collecting and analyzing numerous samples each day, etc.). Knowledge of the processes and the major constiturents provided adequate characterization of the supernate.

Analysis of samples for minor constituents, such as TCLP metals, has, nevertheless, been performed on occasion to provide data for special studies. A thorough search of sampling records [14] identified the limited number of analyses presented in Tables II-IV. The majority of the data were developed for use in evaluating the corrosiveness of supernate [15], for evaluating potential feeds for ITP [16,17] and for Saltstone [18]. In samples collected before 1990, mercury, chromium, silver and lead were the only hazardous components for which analyses were completed. Samples collected in the last $2-4$ years are the only ones for which analyses are included for all of the TCLP metals.

High Level Waste supernate can generally be grouped into several categories based on the operations in which the supernate is involved, the origin of the supernate, and the quantities of chemical constituents and radioisotopes present. A review of the fill history of the tanks during the periods in which the samples were drawn [19,20] allows grouping of the samples into categories of normal storage and evaporation operations, remnants of waste removal operations, and the intank demonstrations of the DWPF feed preparation steps. The concentration of the hazardous and other constituents are different in each supernate, depending on the stage of the process. By grouping supernates into categories based on Tank Farm operations, the limited amount of sample data provides the most conservative snapshot of the concentrations of the hazardous components. As part of the management of HLW, these supernates are eventually blended through combination of the inventories and evaporation to minimize the overall quantity of waste. The distinction between the various types of supernate becomes less clear, so that the characteristics of the blend approach those of an overall, average inventory.

Supernate from the Canyon facilities that is routinely handled during the normal storage and evaporation operations is considered Traditional Supernate (TS). Supernate that has very low concentrations of components is categorized as Dilute Supernate (DS). Supernate that has been generated as a result of the sludge processing (including aluminum dissolution) is termed Sludge Processing Supernate (SPS). Maximum and average concentrations within each supernate category are presented in Table $\mathrm{V}$. The blend of the three types of supernate is categorized as Average Supenate (AS), and the composition for this category is also shown in Table V. 
WSRC-TR-94-0297

Revision 1

Page 12 of 29

\section{Traditional Supernate}

Traditional supernate contains iarge quantities of radioisotopes and non-radioactive constituents. Fresh (unevaporated) supernate and supernates that have been partially or highly concentrated, as well as any combination of these are considered TS. Supernate used to slurry sludge for transfer to SP is also considered TS, because, in the limiting case, use of Dilute Supernate as the slurry medium results in a mixture with the interstitial liquid in the sludge, which is TS. The ${ }^{137} \mathrm{Cs}$ concentration in current TS ranges from $0.99 \mathrm{Ci} / g a l$ to $18 \mathrm{Ci} / \mathrm{gal}$ [21], while historical results show ${ }^{137} \mathrm{Cs}$ concentrations as high as $44 \mathrm{Ci} / \mathrm{gal}$. Traditional Supernate is currently stored in Tanks 1-15, 25-39, 41, and 43-47.

The data presented in Table II are from samples of unevaporated supernate, partially evaporated supernates, supernates which have had as much water removed as possible, and mixtures of the three. The data span both aged and relatively fresh waste, as well as waste generated in both PUREX and HM processes. The two major sets of samples $[15,17]$ do provide a similar cross-cut of the various stages of supernate processing. The average of the sample data is, therefore, representative of the concentration of $\mathrm{Hg}, \mathrm{Cr}, \mathrm{Ag}$ and $\mathrm{Pb}$ in average $\mathrm{TS}$. The average value for the remaining four TCLP metals is not truly significant because data for these constituents were only available from one group of samples [17], the concentrations were quite low, and the detection limits for As and Se were high. An upper limit for the concentration of each species is set to the highest value observed in the sample data, since TS in other tanks is chemically similar.

The concentration of mercury in samples of TS has been observed to vary significantly, ranging from $<10 \mathrm{mg} / \mathrm{to} 340 \mathrm{mg} /$. Samples drawn and analyzed in the 1970's reflected higher Hg levels than did samples collected in the 1990's. Part of this difference in the magnitude is due to losses of mercury into the evaporator overheads through volatilization. The high concentration of hydroxide in current inventories of supernate reflect numerous passes through the evaporator, during which a small quantity of elemental mercury would be evaporated. Part of the difference may also be attributable to changes and improvements in analytical techniques and instruments. The earlier samples also reflected greater variation in $\mathrm{Hg}$ concentration than did recent samples, mostly due to the collection of samples from tanks that had significantly more mixing of supernates, as opposed to tanks that have essentially remained stagnant for the last few years. The concentration of $\mathrm{Hg}$ in average TS is estimated to be $95 \mathrm{mg} /$, with an upper value of $340 \mathrm{mg} /$.

The chromium concentrations in samples of TS were also observed to vary over a wide range, from 10 to $680 \mathrm{mg} /$, further reflecting the mixing due to transfer and combination of supernates. The concentrations are higher than those for $\mathrm{Hg}$ due to chromium's presence in the alkaline solution as the relatively soluble $\mathrm{CrO}_{4}=$ ion. Being more soluble, the chromate ion concentration can increase further during the cycles of evaporation. The $\mathrm{Cr}$ concentration in average TS is $\mathbf{2 2 0}$ $\mathrm{mg} / \mathrm{l}$.

The concentration of silver in Traditional Supernate samples has not been observed above $4 \mathrm{mg} /$, with an average value of $0.59 \mathrm{mg} /$. Lead was also typically observed at low concentrations, but there have been relative extremes in the sample data. The concentration of $\mathrm{Pb}$ in average TS is 18 $\mathrm{mg} /$, with a maximum observed value of $58 \mathrm{mg} /$. Analysis of recent TS samples for lead have resulted in high detection limits, but still less than the maximum historical value.

Data for the concentration of the remaining TCLP metals in TS were only available from samples collected recently for the study documented in References $[16,17]$. The maximum value observed for barium, which is present due to formation from the decay of cesium, was $1.4 \mathrm{mg} /$. Cadmium 
WSRC-TR-94-0297

Revision 1

Page 13 of 29

concentrations ranged from 0.1 to $0.75 \mathrm{mg} /$. Concentrations of arsenic and selenium were not determined due to interferences in the analytical instrumentation, but minimum detection limits of 19 and $235 \mathrm{mg} /$, respectively, were observed. The low concentrations of cadmium and barium are consistent with process knowledge that these metals are not used in any of the processes that generate waste and are only present as fission products.

No studies were identified in which the benzene concentration of waste has been measured. However, representative samples of the unneutralized waste streams collected from the waste generators were analyzed for total carbon [6]. The maximum concentration observed was $1620 \mathrm{mg}$ $C$ per liter. The organic solution used in the Canyons is typically 30\% TBP and 70\% n-paraffin. Benzene as an impurity in the n-paraffin is limited to $0.2 \%$ [22]. Assuming that all the carbon was due to the TBP/n-paraffin mixture only (i.e., neglecting carbonate and oxalate), the fraction due to benzene would be $2.3 \mathrm{mg} \mathrm{C}$ per liter. This translates to a maximum benzene concentration of 2.5 $\mathrm{mg} / \mathrm{l}$ in fresh waste. Samples from fresh waste receipt tanks in F-Area showed a maximum total organic carbon concentration of $220 \mathrm{mg} /$ [23]. If this were assumed to be all due to the n-paraffin with the benzene impurity, the benzene concentration in the supernate would be $2.2 \mathrm{mg} /$. Process knowledge indicates that agitation of the waste during transfer to the Tank Farm and the ventilation in the pump tank and the fresh waste receipt tank acts to strip any organics from solution. Benzene remaining in solution would be stripped upon evaporation, so concentrated supernate would not have any benzene. Thus, a conservative estimate for benzene concentration in fresh TS is $<3 \mathrm{mg} /$.

\section{Dilute Supernate}

Dilute Supernate consists mainly of waste from RBOF/RRF, with occasional dilute waste from other facilities (e.g., tritiated water from Reactor heat exchanger cleanout [24]). Supernate remaining from the waste removal and tank cleaning activities in the mid 1980's is also categorized as DS. Dilute Supernate is stored in the Type IV tanks. (Periodically, DS from the Reactor Basins/Sand Filters is sent to Tank 47, where the DS mixes in with and takes on the characteristics of TS.) The quantities of solids in Dilute Supernate are typically very small (except for Tank 19). The ${ }^{137} \mathrm{Cs}$ concentration of DS ranges from 1.2E-4 to $3.5 \mathrm{E}-2 \mathrm{Ci} / \mathrm{gal}$. There is no means of increasing the concentration of the solids in the tanks, since DS is permanently transferred out of the Type IV tanks before being evaporated.

Only a few analytical results for hazardous constituents in samples of DS have been recorded, and these are presented in Table III. The only hazardous component for which data are available is Hg. Data for RBOF/RRF waste [6] are included in Table III since this stream represents the bulk of the waste source categorized as DS. Data for the Sand Filter Backwash [6] are also included to represent other streams that have been or will be added to the Type IV tanks. Also included is an estimate of the concentration of the components in the supernate based on waste removal operations. The average $\mathrm{Hg}$ concentration in DS reflects a decrease by a factor of more than 90 from average TS. The factor of 5 is arbitrarily assumed to conservatively estimate the waste removal data shown in Table III.

The mercury concentration in DS is represented by the samples collected from the Type IV tanks following waste removal in the mid-1980's. The low concentration is characteristic of dilution resulting from the large quantities of water used to slurry the waste from the tanks, and ranges from 0.07 to $1.6 \mathrm{mg} /$.

For the remaining TCLP metals, the maximum concentrations of each are set to the highest value in the three data sources. The chromium concentration in DS is assumed to be that of RBOF/RRF 
WSRC-TR-94-0297

Revision 1

Page 14 of 29

waste, and the concentrations of silver, lead and barium are assumed to be at the level in the Sand Filter Backwash. Concentrations of arsenic, cadmium and selenium are assumed to be that of the diluted TS.

No sample analysis data for benzene are available. Benzene is not expected to be present, since, in the past, the Type IV tanks received LHW only, and the supernate from these tanks was fed directly to the evaporators for volume reduction. Present operation does not permit fresh waste (the only potential source of benzene) to be transferred into the Type IV tanks due to constraints on ${ }^{137}$ Cs concentration [25].

\section{Sludge Processing Supernate}

Sludge Processing Supernate is generated as a result of the operations performed to prepare sludge for transfer to the DWPF. The SPS has changing characteristics and is initially a mixture of the various Traditional Supernates used to slurry the waste to the SP tanks. As the aluminum dissolution step and washing steps introduce $\mathrm{NaOH}$ solution and water, respectively, the concentrations of the components are reduced to levels similar to DS by dilution. Analytical data for samples collected from the SP tanks (Tanks 40, 42, and 51) are presented in Table IV.

The sample data taken from Tank 42 during the 1982-1983 demonstration represent the supernates following transfer of the waste into the tank, after aluminum dissolution, and following each of three wash steps. However, mercury and chromium were the only hazardous constituents for which analyses were performed in these samples.

The decanted supernate from the slumy transferred into Tank 42 contained $280 \mathrm{mg} / \mathrm{lof} \mathrm{Hg}$ and 88 $\mathrm{mg} / \mathrm{l}$ of $\mathrm{Cr}$, well within the maximum characterization defined for TS. Because the concentrations are expected to vary for every batch of sludge slurry transferred to SP, the maximum characterization for TS is used to define the SPS. Similarly, the concentrations of the remaining components (except benzene) are assigned the same concentrations as in TS. Because aged wastes are transferred to the SP tanks, any benzene will have been volatilized (as described in earlier sections), so the benzene concentration is negligible.

The concentrations of the hazardous constituents in the SPS generated in the aluminum dissolution step are also assumed to have the same values as in TS. In the demonstration, the $\mathrm{Hg}$ level decreased slightly to $270 \mathrm{mg} /$, whereas $C_{r}$ decreased to $45 \mathrm{mg} /$, reflecting transfer of some mercury and chromium from the sludge solids into the supernate that had been augmented with sodium hydroxide and other solutions [11]. The remaining metals are assumed to follow the same behavior. The ${ }^{137} \mathrm{Cs}$ concentration in the supernate decreased by a factor of 2.8 (from $1.2 \mathrm{Ci} / \mathrm{gal}$ to $0.43 \mathrm{Ci} / \mathrm{gal}$ ); however, no conclusions were drawn from the data to determine if the aluminum dissolution step affected the amount of soluble cesium [10].

In the SPS produced during the washing phases of the process, the concentration of mercury dropped by a factor of more than 8 to approximately $30 \mathrm{mg} /$ for the first two washes, and to $<2$ $\mathrm{mg} / \mathrm{l}$ for the third wash. The chromium concentration in the first wash was reduced to about 2 $\mathrm{mg} /$, and remained less than that for the second and third washes. The ${ }^{137} \mathrm{Cs}$ concentration dropped from $0.43 \mathrm{Ci} / \mathrm{gal}$ to a low of $8.2 \mathrm{E}-3 \mathrm{Ci} / \mathrm{gal}$. 
WSRC-TR-94-0297

Revision 1

Page 15 of 29

\section{Average Supernate}

Average Supernate will resemble TS, since the large majority of the supernate in the Tank Farms is from normal processing of waste. The average ${ }^{137} \mathrm{Cs}$ concentration, based on the data in Reference [21], was calculated to be $5.1 \mathrm{Ci} / \mathrm{gal}$. The average concentrations of mercury, chromium, silver and lead were calculated using the data in Tables II-IV and are shown in Table V. Averages for the remaining TCLP metals were not calculated for the reasons cited earlier regarding lack of data and high detection limits.

\section{Implications for Solid Waste Generation}

Solid waste is generated during the performance of activities associated with management of HLW (e.g., sampling of supernate, maintenance of equipment in radiologically controlled areas, replacement of equipment, etc.). Much of the solid waste consists of items such as protective clothing, plastic for contamination prevention, contaminated tools, etc. Other non-standard items (e.g., transfer piping, pumps, potentially contaminated soil) are generated during infrequent and non-routine activities. Free liquid is administratively prohibited from the waste containers, and absorbent material is added to soak up any excess supernate. Typically, $300-1500 \mathrm{lb}$ of waste per container are generated for disposal during Tank Farm activities [26], with disposal in B-25 or B-12 (5000 lb capacity) containers.

Solid waste contaminated with HLW supernate must satisfy acceptance criteria on the number of curies of several radioisotopes in each waste container before being transferred to the EAV for disposal. The most plentiful radioisotope in HLW supernate is ${ }^{137} \mathrm{Cs}$, which has a limit of 0.76 Ci/container [27] for Low Level Waste (LLW). The effective limit in LLW, however, is $0.62 \mathrm{Ci}$ of ${ }^{137} \mathrm{Cs}$ per container due to the presence of ${ }^{129} \mathrm{I}$, which is more restrictive radiologically because of the relative proportion to ${ }^{137} \mathrm{Cs}$ and the extremely low WAC limits for ${ }^{129}$ [28]. The effective maximum content of ${ }^{137} \mathrm{Cs}$ in Intermediate Level Waste (ILW) is $1.8 \mathrm{CV} /$ container, due to the same considerations as for LLW [28].

Solid wastes are also regulated under the Resource Conservation and Recovery Act (RCRA). Because the supernate is hazardous, solid waste contaminated with supernate is also considered potentially hazardous. For waste to be accepted by the EAV for disposal, the waste containers must be certified as nonhazardous with respect to RCRA requirements for corrosivity, listed components, and toxic characteristics. Regulatory requirements indicate that corrosivity is applicable to aqueous or liquid wastes [3]. Because no free liquid (i.e., $<1 \%$ of any included liquid is unabsorbed) is allowed within a waste container, the hazard of corrosivity does not apply to solid waste generated in the Tank Farms. As defined in the earlier section identifying the hazardous constituents, HLW supernate is not a listed waste, satisfying that requirement.

For the characteristic of toxicity, the TCLP applies. For solid waste, a representative sample of the waste is contacted with a specified volume of a leach solution. For the material to be nonhazardous, the concentration of the regulated components in the leachate must be below the threshold levels presented in Table VI. However, obtaining a truly representative sample from the contents of each disposal container to perform the TCLP is not practically possible.

Alternatively, the results of the TCLP can be simulated, using conservative assumptions and data. The concentrations of the hazardous constituents in the leachate are calculated and compared to the RCRA limits. The information generated from these calculations is used to develop a screening criterion to segregate waste containers that require more detailed evaluation from those containers 
whose contents are definitely nonhazardous. The screening criterion is proceduralized for field implementation and provides a more practical method for documenting that waste is nonhazardous.

The calculations are based on the quantity of ${ }^{137} \mathrm{Cs}$ in the waste container. The discussion in the following paragraphs is for ${ }^{137} \mathrm{Cs}$ loadings of $0.12,0.62$ and $1.8 \mathrm{Ci}$. (For comparison, a review of historical data [29] for solid LLW from the Tank Farms reflects that the average gamma dose rate for containers having detectable gamma translated to a ${ }^{137} \mathrm{Cs}$ loading of $0.12 \mathrm{Ci} /$ container. Eighty five per cent of the containers had no detectable gamma.) The amount of supernate that would have to be included in the container to deposit a given quantity of ${ }^{137} \mathrm{Cs}$ is calculated, knowing the Cs concentration in the supernate. Using the concentration of the most restrictive hazardous component (as defined in the next paragraph), the quantity of that component in the container is calculated. Conservatively assuming that all of the hazardous component is leached from a TCLP sample, the concentration in the leachate as a function of the weight of the waste is calculated. The equations developed to simulate the TCLP are presented in Attachment A.

The most restrictive hazardous component is defined as the component being present in the greatest ratio to the RCRA threshold concentration. The ratios for the various supernates are shown in Table VI. The most restrictive component in TS, SPS and AS is mercury, potentially being present in concentrations 170 times the regulatory limit. For DS, the most restrictive component is chromium.

\section{Traditional Supermate}

The concentration of ${ }^{137} \mathrm{Cs}$ in Traditional Supernate used to determine the volume of supernate in the container was $0.92 \mathrm{Ci} / \mathrm{gal}$. This value is based on the lowest, and thus most conservative, concentration for TS from recently documented data [21] corrected to account for decay from the sample date to two years into the future. (It is assumed that this review will be performed periodically to incorporate new information that becomes available.) At this concentration, the volume of supernate that would deposit $0.12 \mathrm{Ci}$ of ${ }^{137} \mathrm{Cs}$ is calculated to be $0.13 \mathrm{gal}$. A higher ${ }^{137} \mathrm{Cs}$ concentration in supernate requires less supernate to deposit $0.12 \mathrm{Ci}$, consequently depositing less $\mathrm{Hg}$ in the waste container. The mercury concentration in the TS was set to the maximum observed value of $340 \mathrm{mg} /$, providing a limiting case for calculation.

The concentration of $\mathrm{Hg}$ in the leachate from solid waste contaminated with TS is shown in Figure 1 as a function of the ${ }^{137} \mathrm{Cs}$ content and the weight of waste. The curves indicate that for a constant ${ }^{137} \mathrm{Cs}$ loading in a container (essentially fixing the amount of supernate that would be included in a container), the Hg concentration in the leachate decreases asymptotically as the amount of waste increases. This is not unexpected, since the amount of $\mathrm{Hg}$ deposited by the fixed quantity of supernate is distributed more "thinly" as the amount of waste increases. The amount of mercury on a representative sample for a TCLP is less, consequently reducing the level in the leachate. Figure 1 reflects that waste containers having a ${ }^{137} \mathrm{C}$ s content less than or equal to 0.12 $\mathrm{Ci}$ (from TS contamination) and containing more than $97 \mathrm{lb}$ of waste will not exceed the $\mathrm{Hg}$ limit of $0.2 \mathrm{mg} /$ in the leachate. Similarly, the leachate for all containers with less than $0.62 \mathrm{Ci}$ of ${ }^{137} \mathrm{Cs}$ and more than $500 \mathrm{lb}$ of waste will contain less than $0.2 \mathrm{mg} / \mathrm{lof} \mathrm{Hg}$. Finally, leachate from a waste payload of over $1500 \mathrm{lb}$ containing $1.8 \mathrm{Ci}$ of ${ }^{137} \mathrm{Cs}$ or less will not exceed the mercury regulatory limit. 


\section{Dilute Supernate}

The most limiting hazardous component in Dilute Supernate is chromium, requiring the solids in $8.6 \mathrm{gal}$ of DS to be deposited on $300 \mathrm{lb}$ of solid waste in order for the concentration in the leachate to exceed $5 \mathrm{mg} /$. The ${ }^{137} \mathrm{Cs}$ concentration in DS is so low that a minimum of $3.4 \mathrm{gal}$ would be required to contaminate solid waste with $0.12 \mathrm{Ci}$ of ${ }^{137} \mathrm{Cs}$. Practical concerns, as well as administrative controls, do not allow the routine withdrawal of such large volumes of supernate from a waste tank (even from one that is very low in radioactivity). As such, there is no plausible means of contaminating solid waste with enough supernate to exceed the Cs or hazardous container limits. Therefore, contamination of solid waste with DS will not cause the waste package to be hazardous.

\section{Sludge Processing Supernate}

Supernate resulting from the transfer of waste into the SP tanks is essentially TS, so the development for TS is applicable.

For SPS generated from aluminum dissolution, the ${ }^{137} \mathrm{Cs}$ concentration is conservatively reduced by a factor of 2 from the initial concentration, but the mercury concentration is kept the same. (The results from the SP demonstration did not conclusively indicate that the process affected dilution of the ${ }^{137} \mathrm{Cs}$, but $\mathrm{Hg}$ remained at roughly the same concentration.) The calculated $\mathrm{Hg}$ concentration in the leachate from SPS contaminated waste is shown in Figure 2. Leachate from waste containers with a ${ }^{137} \mathrm{Cs}$ content less than $0.12 \mathrm{Ci}$ and at least $170 \mathrm{lb}$ of waste will contain less than $0.2 \mathrm{mg} / \mathrm{l}$ of mercury. The curves in Figure 2 also reflect that the $\mathrm{Hg}$ concentration in leachate will be below the regulatory limit for a waste payload in excess of $1000 \mathrm{lb}$ containing $0.62 \mathrm{Ci}$ or less of ${ }^{137} \mathrm{Cs}$ and for $2900 \mathrm{lb}$ or more of waste containing $1.8 \mathrm{Ci}$ or less of ${ }^{137} \mathrm{Cs}$.

For SP wash water, the mercury and cesium concentrations are diluted at approximately the same rate. Based on the data from the demonstration, the concentration of mencury is reduced by more than a factor of 8 in the first wash step. Conservatively using a factor of 4 , the maximum mercury concentration in the first wash water would be $85 \mathrm{mg} /$, requiring the mercury in $1.6 \mathrm{gal}$ of SPS to be deposited in $300 \mathrm{lb}$ of waste to exceed the leachate threshold for $\mathrm{Hg}$. As the supernate is diluted by more washing, this volume increases. As before, several concerns prohibit removal of large quantities of waste from the tanks, precluding the inclusion in a waste container. Thus, SPS generated during the wash cycles will not cause a package of SPS contaminated solid waste to be hazardous.

\section{Implementation as Screening Criteria}

The calculation of the concentrations of the TCLP metals in the leachate is readily implemented in the form of a screening criterion to identify containers of solid waste that are definitely nonhazardous for disposal in the EAV. The most readily available data in the field are the gamma exposure readings for waste containers, which can then be related to the ${ }^{137} \mathrm{Cs}$ content through dose-to-curie calculations. For a given payload of waste in a container, the quantity of ${ }^{137} \mathrm{Cs}$ (and consequently, volume of supernate) that must be present for the concentration of the most restrictive hazardous component in the leachate to reach the TCLP threshold is calculated. The ${ }^{137} \mathrm{Cs}$ loading was calculated for a waste payload up to $5000 \mathrm{lb}$, and the resulting data are presented in Figure 3. 
In Figure 3, for a given waste payload, the $\mathrm{Hg}$ concentration in the leachate from containers with a quantity of ${ }^{137} \mathrm{Cs}$ below the line (for each type of supernate contamination) will be less than $\mathbf{0 . 2}$ $\mathrm{mg} /$. Those containers can, thus, be declared nonhazardous with respect to supernate contamination. Containers with a ${ }^{137} \mathrm{Cs}$ content above the line cannot be declared nonhazardous based on the conservative assumptions applied in the calculations, and would, therefore, be segregated for more detailed analysis.

As a point of reference, waste containers with a payload of $500 \mathrm{lb}$ must contain less than $0.62 \mathrm{Ci}$ of ${ }^{137} \mathrm{Cs}$ for their contents to be nonhazardous due to TS contamination. Alternatively stated, waste packages containing less than $0.62 \mathrm{Ci}$ of ${ }^{137} \mathrm{Cs}$ and with a net payload over $500 \mathrm{lb}$ can be declared nonhazardous for TS contamination. For SPS contaminated waste, a container with a payload of $1000 \mathrm{lb}$ must contain less than $0.62 \mathrm{Ci}$ of ${ }^{137} \mathrm{Cs}$ to be declared nonhazardous.

\section{Comparison with Average Supernate}

The screening criterion developed for TS and SPS contamination incorporated the most conservative concentrations of $\mathrm{Hg}$ and ${ }^{137} \mathrm{Cs}$, thereby providing an upper boundary to develop and apply a screening tool. However, this conservatism is extreme when taken in the context of examining the total waste stream that will be sent to the EAV. As described earlier, the distinction between the various types of supernate becomes less clear over time due to evaporation and intermixing. The characteristics of the inventory gradually approach that of a single, average supernate.

A screening criterion for the total solid waste stream can also be developed using the Average Supernate characterization. The total waste stream is essentially a mixture of all the solid waste contaminated with HLW supernate from various tanks. By extension, the supernate contamination would be a mixture of supernates that are at different stages of evaporation, mixing, etc. The mixture of supernates can, therefore, be represented with the AS characterization.

For Average Supernate, the average TCLP metal concentrations presented in Table V were used to identify the most restrictive component. As summarized in Table VI, the average mercury concentration is 340 times higher than the hazardous limit of $0.2 \mathrm{mg} /$, so $\mathrm{Hg}$ is the most restrictive component. The volume of supernate in a waste container was calculated based on a ${ }^{137} \mathrm{Cs}$ concentration of $4.8 \mathrm{Ci} / \mathrm{gal}$ ( $5.1 \mathrm{Ci} / \mathrm{gal}$ adjusted to account for decay to two years into the future).

For solid waste contaminated with Average Supernate, the maximum ${ }^{137} \mathrm{Cs}$ loading resulting in a mercury concentration in the leachate of $0.2 \mathrm{mg} / 1$ is shown in Figure 4. The screening criteria for TS and SPS contaminated waste are also included in the figure. A comparison of the criteria reflect the extreme amount of conservatism included by using the concentrations of the TCLP metals and ${ }^{137} \mathrm{Cs}$ for the individual TS and SPS streams. For example, in a container with $300 \mathrm{lb}$ of TS contaminated waste, the ${ }^{137} \mathrm{Cs}$ loading would have to be less than $0.37 \mathrm{Ci}$ for the waste container to be screened as nonhazardous. However, for AS contaminated waste (i.e., the overall solid waste stream), the maximum ${ }^{137} \mathrm{Cs}$ loading would be $9.6 \mathrm{Ci}$. Use of the criteria for TS and SPS contaminated waste could result in segregation of more containers than necessary for additional evaluation.

Further examination of the AS criterion in Figure 4 reflects that for a ${ }^{137} \mathrm{Cs}$ loading of $0.62 \mathrm{Ci}$, a payload of more than $20 \mathrm{lb}$ would be nonhazardous (with respect to supernate contamination). Similarly, a payload over $56 \mathrm{lb}$ would be nonhazardous for a ${ }^{137} \mathrm{Cs}$ loading of $1.8 \mathrm{Ci}$. Waste 
minimization practices preclude loading such relatively small quantities of waste into B-12 and B25 containers. Therefore, the total solid waste stream sent to the EAV is nonhazardous, with respect to the supernate contamination.

\section{ACTIONS}

NONE

\section{REEERENCES}

[1] RCRA Part A Permit Application for the SRS

[2] South Carolina Hazardous Waste Management Regulations, R.61-79.261, Appendix II, Method 1311 Toxicity Characteristic Leaching Procedure (TCLP).

[3] South Carolina Hazardous Waste Management Regulations (SCHWMR) R.61-79.261.22(a)

[4] M. Hawkins, "Listed Wastes in:HE Tanks Background Information", ESH-FSG-90007, February 7, 1990.

[5] J. S. Roberts, "Listed Waste From Laboratories - Tiger Team Finding WM/BMP-6", ESHFSG-900315, May 29, 1990.

[6] C. J. Coleman, "Analysis of SRP Waste Streams for Waste Tank Certification", DPST-89-281, March 28, 1989.

[7] B. M. Legler, W. R. McDonell, W. C. Perkins and A. T. Stephenson, "Safety Analysis 200 Area Savannah River Plant, Separations Area Operations, Liquid Radicastive Waste Handling Facilities", DPSTSA-200-10, Sup. 18, August 1988.

[8] D. D. Walker, "Vapor Pressure of Benzene, Methanol, and Isopropanol Over Salt Solutions (U)", DPST-88-661, March 28, 1989.

[9] B. A. Hamm, R. E. Eibling and J. R. Fowler, "Demonstration of In-Tank Sludge Processing, Part I. Aluminum Dissolution, Sludge Washing and Settling Results", DPST-83-668, July 12, 1983.

[10] R. E. Eibling and B. A. Hamm, "Demonstration of In-Tank Sludge Processing, Part II. Effect of Processing on Radionuclides", DPST-83-932, October 19, 1983.

[11] R. E. Eibling and B. A. Hamm, "Demonstration of In-Tank Sludge Processing, Part III: Effect of Processing on Minor Waste Components", DPST-84-795, October 1, 1984.

[12] R. E. Eibling and B. A. Hamm, "Demonstration of In-Tank Sludge Processing, Part IV: Decanted Supernate Composition", DPST-84-798, October 2, 1984.

[13] M. S. Hay and N. E. Bibler, "Characterization and Sludge Washing Studies of Tank 42H Sludge (U)", WSRC-RP-94-730, July 27, 1994. 
WSRC-TR-94-0297

Revision 1

Page 20 of 29

[14] M. C. Chandler and H. Tran, "Supernate Validation and Qualification (U)", HLW-HLE-94-0567, June 27, 1994.

[15] R. S. Ondrejcin, "Chemical Compositions of Supernates Stored in SRP High Level Waste Tanks", DP-1347, August 1974.

[16] G. K. Georgeton and T. E. Pate, "Recommendations for Alternative ITP Feed (U)", WER-CMD-93-0702, March 17, 1993.

[17] D. D. Walker, C. J. Coleman and R. A. Dewberry, "Composition of Tank Farm Supernate Samples (U)", WSRC-RP-93-1009, July 16, 1993.

[18] D. D. Walker and J. R. Fowler, "Chromium Levels in Savannah River Plant Soluble Waste", DPST-87-210, January 7, 1987.

[19] W. S. Cavin and A. T. Crumm, "Waste Transfers and Miscellaneous Additions (U)", WSRC-TR-93-425 Rev. 1, January 21, 1994.

[20] W. S. Cavin and A. T. Crumm, "Fresh Waste Receipts (U)", WSRC-TR-93-426 Rev. 1, January 21, 1994.

[21] J. A. Pike, "Tank Chemistry Report, June 1993 (U)", WER-HLE-930232, July 16, 1993.

[22] n-Paraffin Procurement Specification, Z-SPP-G-00015, December 30, 1992.

[23] D. T. Hobbs, "Organic Content of Tank 33 and Tank 34 Supernate Samples", IWT-LWP-91-033, Rev. 1, March 28, 1991.

[24] G. K. Georgeton, "Impact of 106-K Water Addition on the Waste Chemistry in Tank 17 (U)", WER-WMT-920005, January 2, 1992.

[25] G. K. Georgeton, "Criteria for Acceptance of High Level Liquid Waste Into the 241-F/H Tank Farms (U)", X-SD-G-00001, March 1994.

[26] J. S. Ledbetter, personal communication, May, 1994.

[27] Savannah River Site Waste Acceptance Criteria Manual 1S, "E-Area Vaults Low-Level Radioactive Solid Waste Acceptance Criteria", Procedure 3.10, Rev. Draft B, May 1, 1994.

[28] M. E. Jamison, P. D. d'Entremont, J. S. Clemmons, C. E. Bess and D. F. Brown, "High Level Waste Characterization in Support of Low Level Waste Certification, L. HLW Supernate Radionuclide Characterization (U)", WSRC-TR-94-0290, Rev. 2, July 8, 1994.

[29] C. M. Cole, "Technical Re-Evaluation of EAV 1027 HAD", SWE-SWE-94-0176, April 7, 1994. 
WSRC-TR-94-0297

Revision 1

Page 21 of 29

Table I. Potential Hazardous Constituents in HLW

\begin{tabular}{c} 
Merals \\
\hline $\mathrm{Ag}$ \\
$\mathrm{As}$ \\
$\mathrm{Ba}$ \\
$\mathrm{Cd}$ \\
$\mathrm{Cr}$ \\
$\mathrm{Hg}$ \\
$\mathrm{Pb}$ \\
$\mathrm{Se}$
\end{tabular}

Organics

Benzene

$\mathrm{Ba}$

$\mathrm{Cr}$

$\mathrm{Hg}$

$\mathrm{Se}$ 
WSRC-TR-94-0297

Revision 1

Page 22 of 29

Table II. Concentrations of Hazardous Constituents in Samples of Traditional Supernate

Concentrations (mg/)

\begin{tabular}{|c|c|c|c|c|c|c|c|c|c|}
\hline Tank & Date & Ag & As & $\mathrm{Ba}$ & $C d$ & $\mathrm{Cr}$ & $\mathrm{Hg}$ & $\mathbf{P b}$ & Se \\
\hline 1 & $2 / 21 / 73$ & 3 & & & & 416 & 30 & $<0.2$ & \\
\hline 2 & $2 / 20 / 73$ & 0.04 & & & & 208 & $<20$ & $<0.2$ & \\
\hline 4 & $6 / 23 / 72$ & & & & & 468 & 12 & & \\
\hline 5 & $3 / 1 / 73$ & 0.1 & & & & 364 & 60 & $<0.2$ & \\
\hline 6 & $3 / 1 / 73$ & $<0.04$ & & & & 312 & 320 & $<0.2$ & \\
\hline 8 & $3 / 8 / 73$ & $<0.04$ & & & & 364 & 40 & $<0.2$ & \\
\hline 9 & $1 / 11 / 73$ & 0.3 & & & & 156 & 130 & 5 & \\
\hline 10 & $1 / 5 / 73$ & 0.2 & & & & 104 & 280 & 2 & \\
\hline 11 & $7 / 11 / 72$ & & & & & 260 & 240 & & \\
\hline 11 & $6 / 1 / 80$ & $\therefore$ & & & 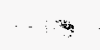 & 156 & & & \\
\hline 12 & $7 / 11 / 72$ & & & & & 104 & 340 & & \\
\hline 13 & $12 / 19 / 72$ & 0.3 & & & & 52 & 120 & 10 & \\
\hline 13 & $9 / 1 / 80$ & & & & & 364 & & & \\
\hline 13 & $6 / 1 / 81$ & & & & & 416 & & & \\
\hline 13 & $10 / 1 / 86$ & & & & & 192 & & & \\
\hline 14 & $1 / 3 / 73$ & 4 & & & & 156 & 110 & 58 & \\
\hline 15 & $12 / 19 / 72$ & 0.1 & & & & 104 & 100 & 6 & \\
\hline 15 & $4 / 1 / 79$ & & & & & 26 & & & \\
\hline 15 & $8 / 1 / 80$ & & & & & 36 & & & \\
\hline 18 & $9 / 7 / 72$ & & & & & 312 & $<20$ & & \\
\hline 18 & $6 / 1 / 80$ & & & & & 468 & & & \\
\hline 21 & $6 / 19 / 72$ & & & & & 104 & 60 & & \\
\hline 22 & $6 / 1 / 86$ & & & & & 120 & & & \\
\hline 24 & $2 / 6 / 73$ & 0.4 & & & & 52 & 120 & 14 & \\
\hline 25 & $7 / 30 / 92$ & $<0.09$ & $<11$ & $<0.02$ & 0.45 & 46 & $<10$ & $<29$ & $<82$ \\
\hline 26 & $8 / 14 / 92$ & 1.14 & $<14$ & 0.39 & 0.75 & 23 & & $<35$ & $<86$ \\
\hline 27 & $7 / 21 / 92$ & 0.53 & $<10$ & 0.2 & 0.43 & 28 & $<10$ & $<24$ & $<63$ \\
\hline 28 & $7 / 21 / 92$ & 0.39 & $<13$ & 0.15 & 0.57 & 93 & $<10$ & $<33$ & $<110$ \\
\hline 29 & $2 / 20 / 86$ & & & & & 572 & & & \\
\hline 29 & $11 / 28 / 92$ & 0.21 & $<19$ & 1.4 & 0.75 & 407 & $<20$ & $<51$ & $<240$ \\
\hline 30 & $3 / 1 / 84$ & & & & & 99 & & & \\
\hline 30 & $11 / 29 / 92$ & $<0.2$ & $<12$ & $<0.04$ & $<0.1$ & 177 & $<20$ & $<20$ & $<120$ \\
\hline 30 & $10 / 1 / 86$ & & & & & 99 & & & \\
\hline 32 & $11 / 29 / 92$ & $<0.2$ & $<10$ & $<0.04$ & $<0.1$ & 117 & $<20$ & $<19$ & $<87$ \\
\hline 35 & $10 / 1 / 86$ & & & & & $<10$ & & & \\
\hline 38 & $11 / 24 / 92$ & $<0.23$ & $<13$ & $<0.05$ & 0.4 & 509 & $<10$ & $<30$ & $<220$ \\
\hline 42 & $6 / 3 / 82$ & & & & & 88 & 277 & & \\
\hline 43 & $8 / 1 / 85$ & & & & & 187 & & & \\
\hline 43 & $11 / 1 / 86$ & & & & & 348 & & & \\
\hline 43 & $11 / 24 / 92$ & $<0.2$ & $<10$ & $<0.04$ & 0.24 & 431 & $<10$ & $<26$ & $<200$ \\
\hline 47 & $7 / 1 / 81$ & & & & & 676 & & & \\
\hline
\end{tabular}


WSRC-TR-94-0297

Revision 1

Page 23 of 29

Table III. Concentrations of Hazardous Constituents in Samples of Dilute Supernate

Concentrations (m/1)

\begin{tabular}{|c|c|c|c|c|c|c|c|c|c|}
\hline Tank & Date & $\mathrm{Ag}$ & As & $\mathrm{Ba}$ & $\mathrm{Cd}$ & $\mathrm{Cr}$ & $\mathrm{Hg}$ & $\mathrm{Pb}$ & $\mathrm{Se}$ \\
\hline 21 & $10 / 9 / 86$ & & & & & & $<0.01$ & & \\
\hline 21 & $9 / 24 / 86$ & & & & & & 1.42 & & \\
\hline 21 & $9 / 22 / 86$ & & & & & & 1.21 & & \\
\hline 21 & $6 / 4 / 86$ & & & & & & 0.071 & & \\
\hline 22 & $5 / 21 / 86$ & & & & & & 1.653 & & \\
\hline RBOF & & $<0.01$ & & 0.04 & & 400 & $<0.001$ & $<1.8$ & \\
\hline $\mathbf{R x}$ & & $<10$ & & 10 & & 10 & $<1$ & 30 & \\
\hline $\mathrm{TS} / 5$ & & 0.117 & 2.489 & 0.052 & 0.084 & 45 & & 3.63 & 26.67 \\
\hline
\end{tabular}

Table IV. Concentrations of Hazardous Constituents in Samples of Sludge Processing Supernate

Concentrations (mg/l)

\begin{tabular}{|c|c|c|c|c|c|c|c|c|c|}
\hline Tank & Date & Ag & As & $\mathrm{Ba}$ & Cd & $\mathrm{Cr}$ & $\mathrm{Hg}$ & $\mathrm{Pb}$ & $\mathrm{Se}$ \\
\hline 40 & $3 / 1 / 93$ & $<0.4$ & & & & & 4.92 & $<2$ & \\
\hline 42 & $10 / 1 / 92$ & & & & & 70 & 2.2 & & \\
\hline 42 & $2 / 17 / 92$ & & & & & & 18.5 & & \\
\hline 42 & $1 / 4 / 83$ & & & & & 1.4 & 1.9 & & \\
\hline 42 & $10 / 22 / 82$ & & & & & 1 & 30 & & \\
\hline 42 & $9 / 10 / 82$ & & & & & 2.1 & 32 & & \\
\hline 42 & $7 / 30 / 82$ & & & & & 45 & 269 & & \\
\hline 51 & $3 / 1 / 93$ & $<4.4$ & & & & & 9.24 & $<2.2$ & \\
\hline 51 & & & & & 0.8 & 65 & & 12 & \\
\hline
\end{tabular}


WSRC-TR-94-0297

Revision 1

Page 24 of 29

Table V. Characterization of Hazardous Constituents in HLW Supernates

Hazardous Component Concentrations ( $\mathrm{m} g /$ )

\begin{tabular}{|c|c|c|c|c|c|c|c|}
\hline \multirow[b]{2}{*}{ Component } & \multicolumn{2}{|c|}{ Traditional S'nate } & \multicolumn{2}{|c|}{ Dilute S'nate } & \multicolumn{2}{|c|}{ Sludge Processing S'nate } & \multirow{3}{*}{$\frac{\text { Average S'nate }}{11}$} \\
\hline & Maximum & Avernge & Maximum & Average & Maximum & Average & \\
\hline Ag & 4 & 0.58 & 10 & - & 4 & - & \\
\hline As & 19 & 12 & 2.5 & 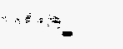 & 19 & - & - \\
\hline $\mathrm{Ba}$ & 1.4 & 0.26 & 10 & - & 1.4 & - & - \\
\hline$\overline{c d}$ & 0.75 & 0.42 & 0.084 & & 0.75 & - & - \\
\hline $\mathrm{Cr}$ & 680 & 220 & 400 & - & 680 & - & 200 \\
\hline $\mathrm{Hg}$ & 340 & 95 & 1.6 & 0.77 & 340 & - & 69 \\
\hline $\mathbf{P b}$ & 58 & 18 & 30 & - & 58 & - & 16 \\
\hline Se & 240 & 130 & 27 & - & 240 & - & - \\
\hline
\end{tabular}

- Indicates that value was not calculated

Table VI. Relative Importance of Hazardous Constituents in HLW Supernates

\begin{tabular}{|c|c|c|c|c|c|}
\hline \multirow[b]{2}{*}{ Component } & \multirow[b]{2}{*}{$\begin{array}{l}\text { RCRA Limit } \\
(\mathrm{mg} /)\end{array}$} & \multicolumn{4}{|c|}{ Ratio to RCRA Concentration } \\
\hline & & Traditional & Dilute & $\begin{array}{l}\text { Sludge Processing } \\
\text { Wash Water** }\end{array}$ & Average \\
\hline $\mathrm{Ag}$ & 5 & 0.80 & 2.0 & 0.20 & 0.22 \\
\hline As & 5 & 3.8 & 0.50 & 0.95 & - \\
\hline $\mathrm{Ba}$ & 100 & 0.014 & 0.10 & 0.0035 & - \\
\hline $\mathrm{Cd}$ & 1 & 0.75 & 0.084 & 0.19 & - \\
\hline $\mathrm{Cr}$ & 5 & 140 & 80 & 34 & 40 \\
\hline $\mathrm{Hg}$ & 0.2 & 1700 & 8.0 & 420 & 340 \\
\hline $\mathrm{Pb}$ & 5 & 12 & 6.0 & 2.9 & 3.2 \\
\hline Se & 1 & 240 & 27 & 60 & - \\
\hline
\end{tabular}

** Ratios for Initial Slurry Receipt and Aluminum Dissolution supernates is the same as for Traditional Supernate. Ratio for Wash Water is based on one fourth of Traditional Supernate values.

- Indicates that value was not calculated 
WSRC-TR-94-0297

Revision 1

Page 25 of 29

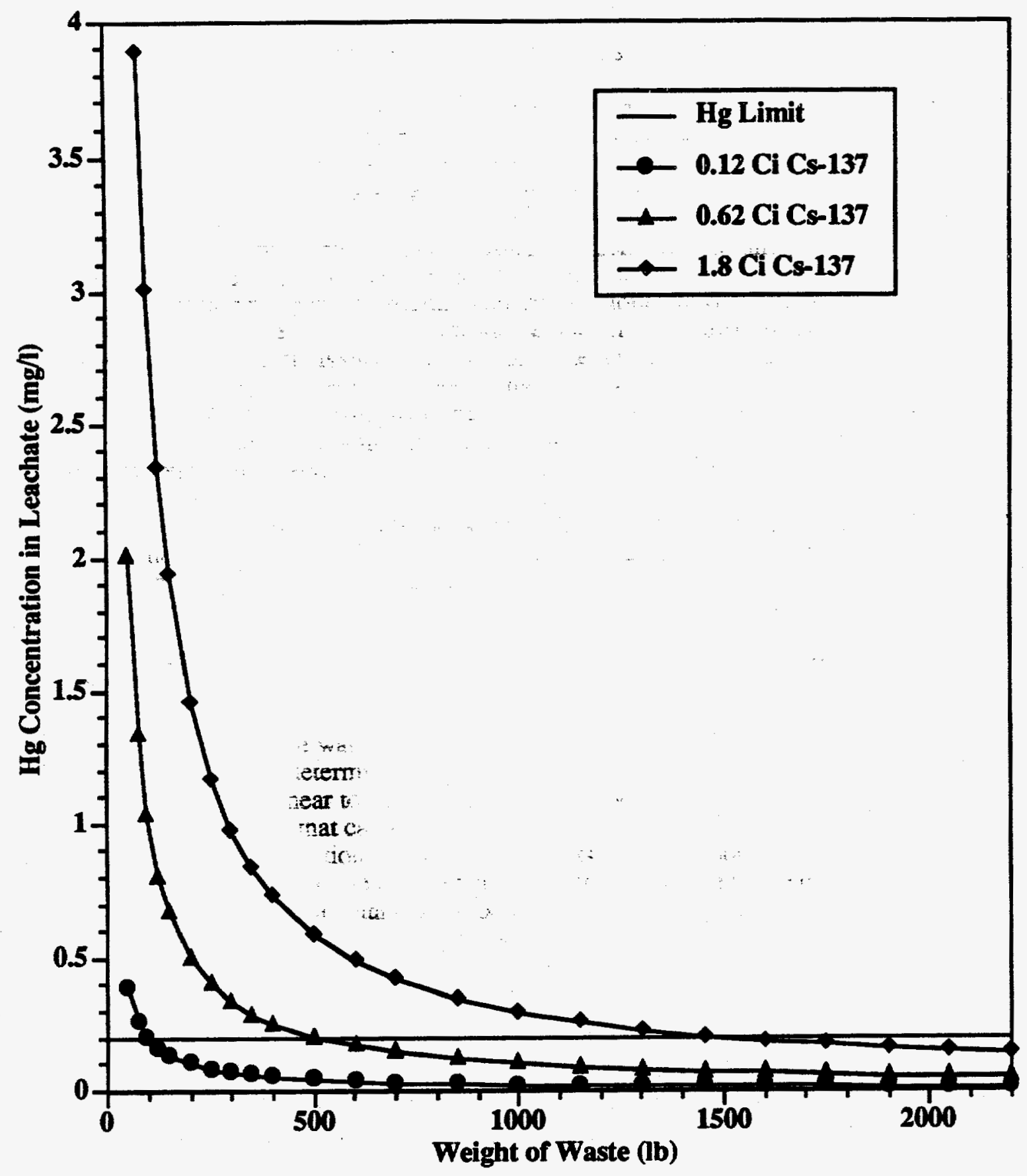

Figure 1. Simulated TCLP Leachate for TS Contaminated Solid Waste 
WSRC-TR-94-0297

Revision 1

Page 26 of 29

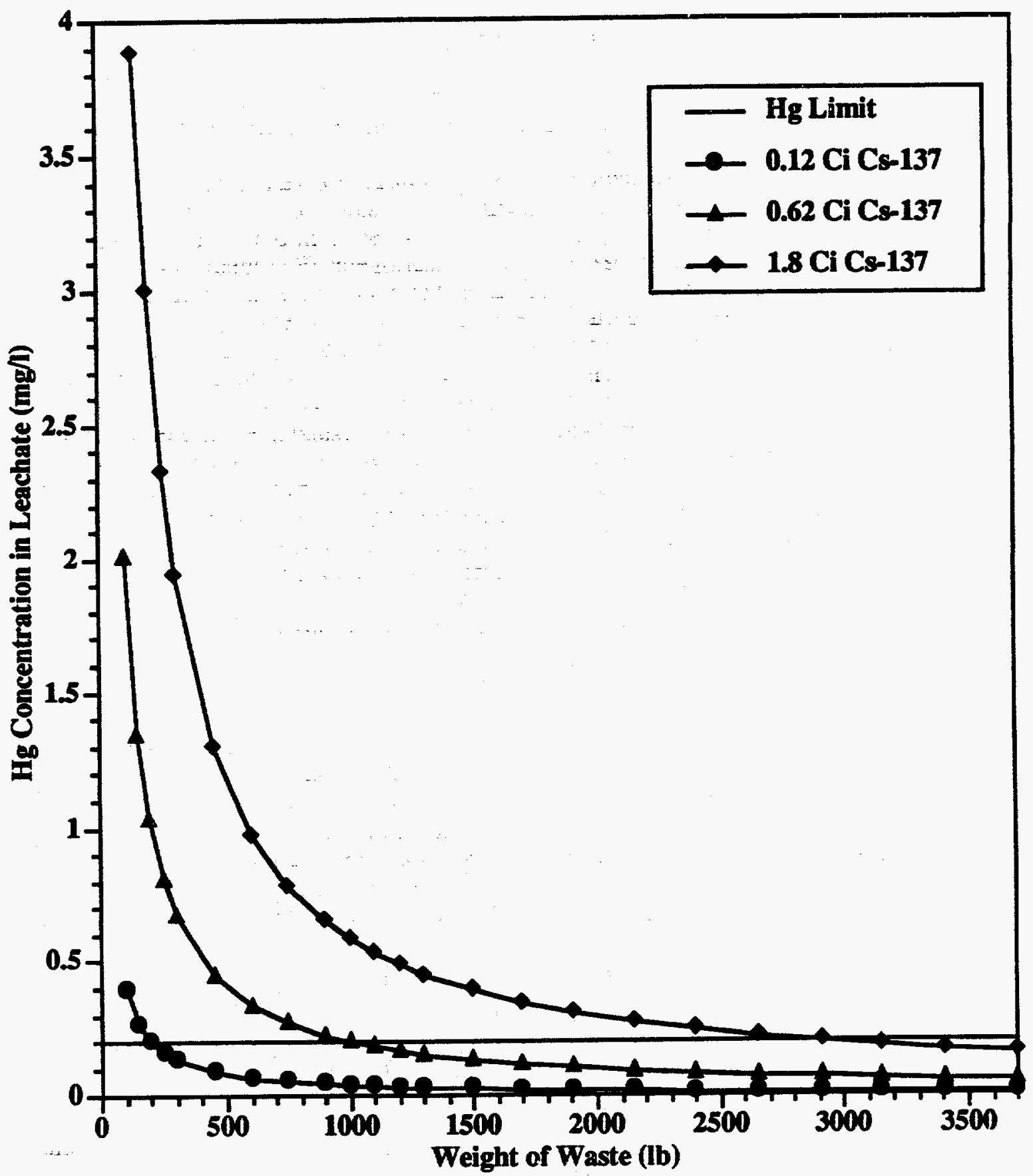

Figure 2. Simulated TCLP Leachate for SPS Contaminated Solid Waste 
WSRC-TR-94-0297

Revision 1

Page 27 of 29

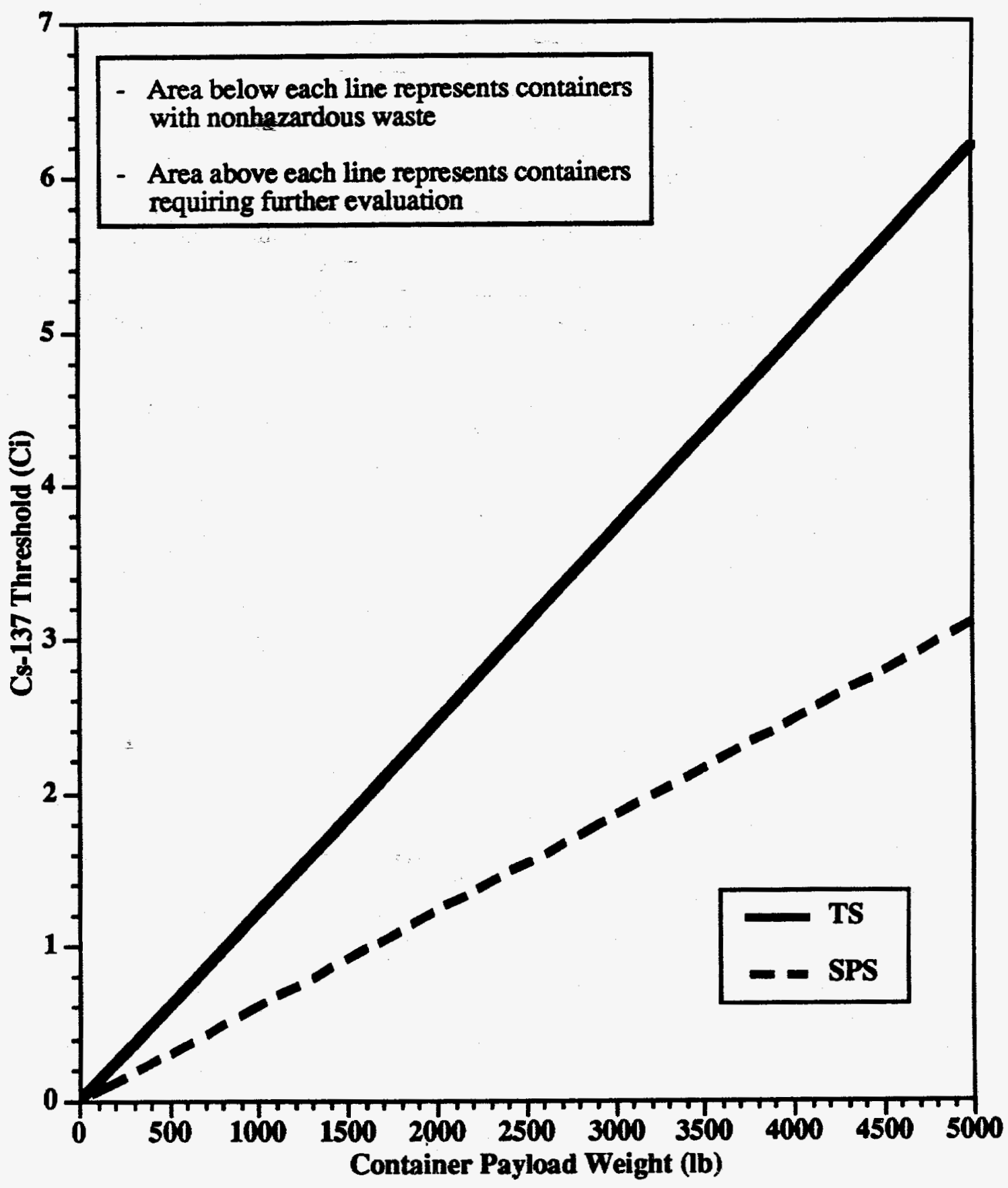

Figure 3. Screening Criteria for Supernate Contaminated Solid Waste 


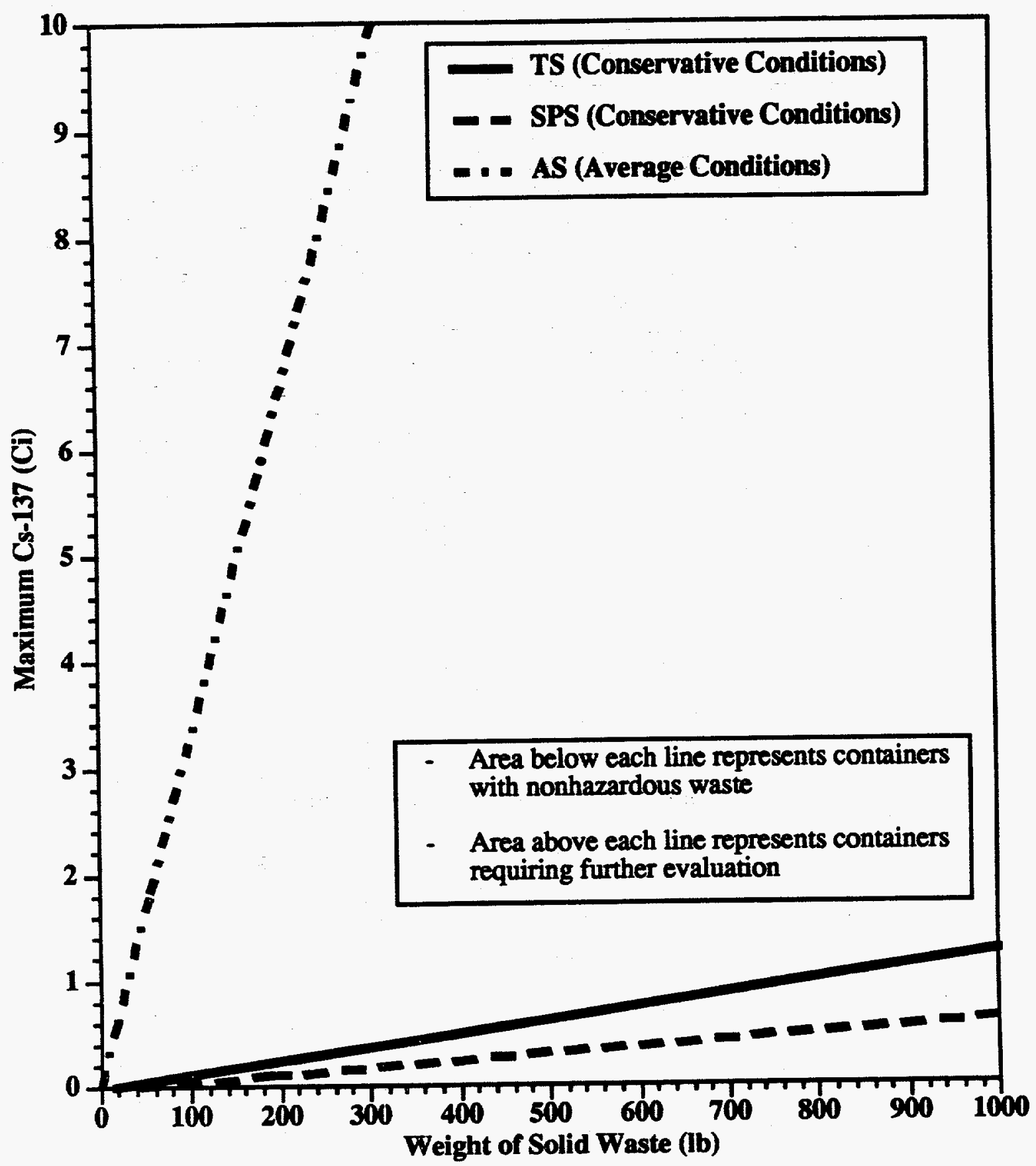

Figure 4. Comparison of Individual Supernate Criteria to Criteria Based on Average Supernate Characterization 
WSRC-TR-94-0297

Revision 1

Page 29 of 29

\section{ATTACHMENT_A}

\section{Calculation of Limiting Hazardous Constituent in Leachate}

Definition of Variables -

$V$ volume of supernate in waste container

c concentration of hazardous component in the supernate

Y mass of hazardous constituent in the waste container

W weight of waste in the waste container

$x$ mass fraction of hazardous constituent in the waste container

y mass of hazardous constituent in the representative sample

$z$ concentration of hazardous constituent in the leachate

$I_{E}$ density of leaching solution

Given a volume $\mathrm{V}$ of supernate included in the container, the mass of the hazardous component in the waste is calculated from Eqn. (1).

$$
\mathrm{Y}=\mathrm{V} \mathbf{c}
$$

The mass fraction of the hazardous component within the waste is then calculated from

$$
x=\frac{Y}{W}
$$

so the amount of hazardous constituent that would be in a $100 \mathrm{gm}$ representative sample of the waste is calculated in Eqn. (3).

$$
y=(100 \mathrm{gm}) x
$$

The two possible extraction fluids are dilute solutions of either glacial acetic acid or a mixture of glacial acetic acid and $\mathrm{NaOH}$ [2]. The density of the solution is conservatively assumed to be 1.05 $\mathrm{gm} / \mathrm{ml}$ (the density is actually close to $1.0 \mathrm{gm} / \mathrm{ml}$ ). The amount of extraction solution is specified as 20 times the weight of the representative sample. Assuming that all the hazardous constituent is dissolved in the extraction liquid, the concentration of the constituent is

$$
z=\frac{y}{\left(\frac{20(100 \mathrm{gm})}{\rho_{E}}\right)}
$$

Inserting Eqns. (1), (2) and (3) into Eqn. (4) and simplifying,

$$
z=\frac{\rho_{E}(100 \mathrm{gm}) \frac{V c}{W}}{20(100 \mathrm{gm})}=\frac{V c \rho_{E}}{20 \mathrm{~W}}
$$

